\title{
Muscle cramps - a mini review of possible causes and treatment options available with a special emphasis on diabetics - a narrative review
}

\begin{abstract}
Muscle cramps are characterized by sudden, painful involuntary contraction of the muscles. The cramps sometimes become disabling and the prevalence is more in the elderly. The etiology of the cramps are diverse and some time the cramps are idiopathic. There are many underlying pathophysiological disorders like hypocalcemia, hypomagnesemia, hypothyroidism, and hepatorenal dysfunction which causes muscle cramps. Similarly, diabetes mellitus results in muscle cramps due to electrolytic imbalance, hypoglycemia, peripheral arterial insufficiency, and neuropathies. Persistent muscle pain in diabetic patients degrades the quality of life of those patients. Although the pathophysiology and etiology of the muscle cramps are understood to some extent, the same is less explored from diabetes mellitus perspective. Hence the objective of this review is to explore the underlying factors responsible for muscle cramps in diabetes so that proper strategy for pharmacotherapy can be made to manage this condition. (Clin Diabetol 2019; 8, 6: 310-317)
\end{abstract}

Key words: muscle cramps, diabetes mellitus, hypocalcemia, hypomagnesemia

Address for correspondence:

Dr. Sayak Roy, MRCP (Ireland)

Department of Internal Medicine

Medica Superspeciality Hospital, Kolkata

West Bengal, 700027, India

Phone: +919051626890

e-mail: sayak.roy.123@gmail.com

Clinical Diabetology 2019, 8, 6, 310-317

DOI: $10.5603 /$ DK.2019.0029

Received: 18.07.2019

Accepted: 08.12.2019

\section{Introduction}

Muscle cramps are generally painful involuntary contraction of muscles caused due to ectopic discharge from nerve terminals or nerves [1]. These muscle cramps differ from benign to sometime disabling. Hence, a detailed history and neurological examination is indispensable to identify diverse etiology of the muscle cramps [2]. According to a cross sectional study on 365 older outpatients in UK, $50 \%$ of them reported frequent muscle cramps [3]. In another review $56 \%$ out of 515 old patients reported to have muscle cramps at least once in a week [4]. However, a very limited epidemiological data is available on the prevalence of muscle cramps in patients with diabetes and in general population [5]. A demographic study conducted on diabetic patient in Toronto revealed, a $75.5 \%$ of type 2 diabetic and $57.5 \%$ of type 1 diabetic patients encountered muscle cramps [6]. In the above study, diabetic neuropathy was found to be the most important independent risk factor for muscle cramps. Bharucha et al. in their door-to-door survey analysis in a parsi community found diabetes to be the most common cause for non-compressive neuropathy [7]. The high rate in Parsis is probably related to aging population, and in urban slum, it may be due to nutritional and adverse environmental factors and needs further study. Saha et al. in his study showed an increase in age and sex specific prevalence of neurological disorders in both sexes although there was a minor dip in female population in their fourth and fifth decades [8]. A population-based survey by Gouri-Devi et al. showed a two times high rate of neurological disorders as compared to urban parts but the reasons could not be determined [9]. 
In diabetes mellitus, muscle cramps are a common symptom which may occur due to electrolytic imbalance, hypoglycemia, peripheral arterial insufficiency and neuropathies. These cramps generally occur in the lower extremities and the patients mostly experience it during night. The symptoms range from cramping muscle pain to burning sensation. Muscle infarction is a rare cause of acute muscle pain in diabetic patients [10]. The cramp-fasciculation and peripheral neuropathies are closely associated with muscle cramps [2]. Besides, hypocalcemia, hypomagnesemia, hypothyroidism, and hepatorenal dysfunction may also contribute to muscle cramps. Sometime these muscle cramps are idiopathic which vary in presentation from subject to subject. There are only few studies available which completely address the issue of muscle cramps in relation with diabetes. Hence, the objective of this review is to discuss completely on the pathology, cause and possible treatment modalities of muscle cramps with special attention on diabetes.

\section{Pathophysiology and etiology of muscle cramps}

Various theories have been postulated to explain the pathophysiology of muscle cramps [11].

\section{General pathophysiology of cramps}

\section{Old theories}

\section{Psychosomatic theory}

The psychosomatic disorder causing muscle cramps is one among the major theories postulated by olden French and German neurologist. As per Féré, muscle cramps result due to heavy exercise, nervousness, neurasthenia, hysteria or epilepsy [12].

\section{Vascular theory}

In the 1920s, vascular insufficiency during muscle contraction was believed to be the major cause of muscle cramps. Accumulation of lactic acid was believed to cause persistent involuntary contraction and muscle cramps [13]. Vascular theories were believed until the mid-1980s in central Europe. However, these theories are rejected by Santler, based on clinical common sense [14, 15].

\section{Deformity theory}

Static origin of muscle cramps is one among the theories postulated in the past responsible for muscle cramps. Muscle cramps in feet and calves' muscle are believed to be due to static deformities of the back, the pelvis, legs and feet $[16,17]$. As rest removes the sources of irritation, this theory supports the argument of healing effect of the rest on exercise induced muscle cramps [18].

\section{Myogenic theory}

Another theory is postulated by Strümpell [19] who said that muscle cramps have a myogenic origin, like myotonia. He postulated that the contraction of the sarcoplasma in the muscle fibrils cause muscle cramps. Hence this pain resembles violent colics. This view was opposed by Grund, 1971 [20].

\section{ATP deficiency theory}

It is a well-known fact that muscle cramps occur due to lack of relaxation of skeletal muscles. Upon relaxation of skeletal muscles, myosin fibers get dissociated from actin. For this process to take place ATP must get attached to myosin. A paucity of ATP produces insufficient dissociation of myosin from actin [21]. In one recent study, L-carnitine proved to improve the prognosis cirrhotic cramps [22].

\section{New theory \\ Neural origin theory}

Very recent theory on muscle cramps was neural origin of cramps. A strong clinical association exists between muscle cramps and lower motor neuron diseases like amyotrophic lateral sclerosis, neuropathy and radiculopathy. These are not associated with upper motor neuron or muscular disease. Spinal reflex produced due irritation of intramuscular sensory nerve endings by toxins like arsenic, alcohol, diabetes mellitus and cholera. This leads to prolonged irritation of anterior horn nerve cells there by result in muscle cramps [23]. In another study, Klimke reported sympathetic stimulation of skeletal muscle by creatine or neurovegetative irritation is a major factor of muscle cramps [24]. The loss of motor neurons with increased age leads to muscle cramps in older people [2]. This result is espoused by a case-control study where older subjects with nocturnal cramps found to have lesser lower limb muscle-strength compared to their counter parts without nocturnal cramps [25]. Tendon shortening in advanced aged individuals due to long immobility leads to excitation of nerve terminals which in turn leads to the development of cramps.

\section{Site of origin}

The site of origin of the muscle cramps plays pivotal role in pathophysiology of muscle cramps. Many studies have suggested that muscle cramps result from a rapid penetrative firing of motor unit action potential which are set at a rate much higher than those needed for involuntary contractions. This is due to spontaneous discharges of motor nerve ending rather than a central or muscular origin [2]. The factors which contribute to muscle cramps include excitability of anterior horn cells or the intramuscular motor nerve endings. 


\section{Etiology of muscle cramps}

Table 1 is a crisp presentation of etiology of muscle cramps. Table 1 summarises few of the huge number of etiologies of muscle cramps in a diabetic population and it has been found that most of them are either due to idiopathic reason or due to underlying peripheral neuropathy $[6,31]$. A study of outpatient veterans reported leg cramps in $75 \%$ of those with peripheral vascular disease, $63 \%$ of those with hypokalemia, and $62 \%$ of those with coronary artery disease [5].

There is a famous case report of a 56 year old poorly controlled type 2 diabetes who experienced severely painful muscle cramps of bilateral upper and lower extremity shortly after analogue insulin injection the cause of which had been attributed to a $16 \%$ drop in potassium due to insulin injection from baseline on top of an already existing neuropathy in that patient [26]. A similar finding was observed long back in Duke University Medical Centre way back in 1992 [32].

Diabetic neuropathy and nephropathy were reported to have been associated with high incidence of muscle cramps but neuropathy seems to be an independent risk factor as well as the type of diabetes like type $2>$ type 1 [6]. Towards the end of hemodialysis one third of the patients experience muscle cramps [33] which gets subsided by volume expansion with hypertonic dextrose or saline solution. Intentionally changing the sodium concentration of the dialysis fluid during the dialysis is sometimes used to preserve the plasma volume towards the end of the dialysis. This process reduces the incidence of muscle cramps in some cases $[34,35]$. It is also known that any acute extra cellular fluid volume contraction cause muscle cramps. This occurs during excessive vomiting, diarrhoea or excessive sweating or diuretic therapy. About 60 percent of patients with cirrhosis reportedly have leg cramps, most of whom are older patients with advanced disease [29]. Chronic venous insufficiency also results in cramps but strangely enough the treatment has not lead to the slowing down of the course of muscle cramps [11]. Nerve damage from cancer treatment may be a cause of legs cramps, with a small study demonstrating that leg cramps were present in 82 percent of patients with cancer [30].

Muscle cramps caused due to adverse event of number of drugs, however, very few drugs reported to have caused leg cramps. The medication with intravenous iron source, raloxifene (Evista), naproxen (Naprosyn), conjugated estrogens, and teriparatide (Forteo) produced very low incidence of leg cramps [31]. Besides, clonazepam (klonopin), celecoxib (Celebrex), and gabapentin (Neurontin) also produce leg cramps, although they are prescribed for treatment
Table 1. Etiology of muscle cramps (decreasing frequency in terms of association to diabetes) [11, 26-30]

\begin{tabular}{|c|c|}
\hline SI. No & Cause \\
\hline 1 & Idiopathic \\
\hline 2 & Peripheral neuropathy \\
\hline 3 & Peripheral vascular diseases \\
\hline 4 & Cardiovascular disorders \\
\hline 5 & $\begin{array}{l}\text { End stage renal disease on maintenance } \\
\text { hemodialysis and acute electrolyte changes }\end{array}$ \\
\hline 6 & $\begin{array}{l}\text { Insulin induced acute drop in serum } \\
\text { potassium levels }\end{array}$ \\
\hline 7 & Cirrhosis of liver \\
\hline 8 & Venous insufficiency \\
\hline 9 & Cancer chemotherapy \\
\hline 10 & $\begin{array}{l}\text { Drug induced - intravenous iron sucrose, } \\
\text { raloxifene, conjugated estrogens, naproxen, } \\
\text { teriparatide, daclizumab, levosalbutamol, etc. }\end{array}$ \\
\hline 11 & $\begin{array}{l}\text { Neurological disorders like amyotropic lateral } \\
\text { sclerosis, parkinsonism, etc. }\end{array}$ \\
\hline 12 & Lumbar canal stenosis \\
\hline
\end{tabular}

of muscle cramps. It is also believed that diuretics like hydrochlorothiazide cause leg cramps [36].

Muscle cramps are associated with various diseases which cause damage to lower motor neurons including amyotrophic lateral sclerosis (ALS) [37], peripheral nerve injury [38], and polyneuropathies [39]. Cramps are more common in the above diseases compared to other lower motor neuron ailments although the cause is not very clear till date.

Due to metabolic changes during pregnancy $30 \%$ of women in their third trimester of pregnancy experience muscle cramps [40].

\section{Pathophysiology of muscle cramps in diabetes}

Data is sparse on explaining the pathophysiology of muscle cramps in diabetics and more specifically why it actually happens mostly in early morning hours. In a rodent model study on C57BL/6 male mice, it was seen that mice quadriceps centralized nuclei and caspase 3 protein increased significantly reflected by a $p$ value of $<0.05$ in both cases [41]. The data suggested that diabetes induced muscle damage by promoting a profibrotic profile. In another human study on muscle biopsy it was found that rate of ADP depletion with rest $(p=0.008)$ and oxidative phosphorylation $(p=$ 0.046 ) in type 2 diabetic gastrocnemius muscle was impaired as evidenced by ${ }^{31}$ phosphorus magnetic reso- 
nance spectroscopy [42]. L-carnitine deficiency might also play an important role in diabetic mitochondrial dysfunction which has been frequently associated with muscle cramps as the deficiency has been linked to insulin resistance [43].

Mitochondrial dysfunction is another key player in causing muscle cramps in diabetics [44]. One study revealed that almost two thirds of diabetic patients suffer from muscle cramps and often they seem to harbour diabetic neuropathy [6]. Another important aspect is a high prevalence of dyslipidemia in diabetic patients for which statins have to be used and this statin cause a reduction of coenzyme Q10 which is often responsible for the muscle cramps $[45,46]$. The other suggested etiologies for muscle cramps in diabetics are hypoglycemia, peripheral arterial disease, neuropathy or electrolyte imbalances [47]. In an epidemiological study it was seen that neuropathy and not nephropathy as well as type of diabetes (type $2>$ type 1 ) were important independent predictors of muscle cramps [6].

\section{Characteristic changes of muscles at molecular level in diabetes}

Muscle related pathologies in diabetics have multiple reasons and these are summarized below.

\section{Genetics}

Gene expression alterations have been reported with type 2 diabetes. In a study, skeletal muscle biopsies taken from male subjects with type 2 diabetes, their first-degree relatives, and healthy controls were investigated at the gene expression level using the microarray technology [48]. An important finding in another study was the substantial increase in expression of genes that are involved in insulin signaling in skeletal muscle from first degree relatives of type 2 diabetics, and the significant downregulation of the same pathway in samples of type 2 diabetic skeletal muscles (Table 2) [49].

\section{Microangiopathy}

Small vessels are often abnormal in the tissues of diabetic patients. In recent years, the center of attention has been focused on the capillary basement lamina, which is a layer of amorphous material chemically resembling collagen coating the exterior of the endothelial cells. There has been widening of the capillary basement lamina in the skeletal muscle biopsies from diabetic patients. The endothelial cells appear unremarkable, but the basement lamina seems greatly widened and is often redundant and laminated with various materials in-between the lamina. In more
Table 2. Significant genetic changes in pathways/functions

\begin{tabular}{lcc}
\hline Gene pathway/function & p-value & Remarks \\
\hline First degree relatives & & \\
Insulin signalling & 0.005 & Up regulated \\
TGF-beta signalling & 0.068 & Up regulated \\
RNA splicing & 0.089 & Up regulated \\
Inorganic anion transport & 0.74 & Down regulated \\
Focal adhesion & 0.14 & Down regulated \\
Inflammatory response & 0.326 & Down regulated \\
pathway & & \\
Type 2 diabetic patients & & \\
Protein modification & 0.979 & Up regulated \\
Cell cycle G1 to S control & 0.676 & Down regulated \\
reactome & & \\
MAPK signalling & 0.002 & Down regulated \\
Insulin signalling & 0.002 & Down regulated \\
G-protein signalling & 0.078 & Down regulated \\
Apoptosis & 0.388 & Up regulated \\
\hline
\end{tabular}

recent years, attention has been directed to the capillary basement lamina, a layer of amorphous material chemically resembling collagen that coats the exterior of the endothelial cells. This layer is located between the blood carrying oxygen and nutrients and the tissues. Widening of the capillary basement lamina in skeletal muscle biopsies from diabetic patients. In any event, the abnormal production of basement lamina appears to be widespread in the capillary bed of patients suffering from diabetes mellitus and these capillary abnormalities have important consequences with respect to many of the lesions that occur in this disease [50].

\section{Mitochondrial dysfunction}

In one recent study, it has been observed that in type 2 diabetic patients the muscle cramps are produced due to impaired bioenergetic capacity of skeletal muscle mitochondria. The study was done by taking the biopsy of vastus lateralis muscle from lean and obese nondiabetic subjects and type 2 diabetic volunteers. The electron microscopy view of the skeletal muscle revealed the presence of smaller mitochondria in type 2 diabetic and obese volunteers compared to their lean counterparts $(p<0.01)$. Similarly, the activity of rotenone-sensitive $\mathrm{NADH}: \mathrm{O}_{2}$ oxidoreductase enzyme was reduced in type 2 diabetic skeletal muscle compared to the healthy subjects. Hence, it was concluded that in the skeletal muscle of diabetic patient the mitochondria lose its bioenergetic capacity. 
Table 3. Differential diagnosis of leg cramps

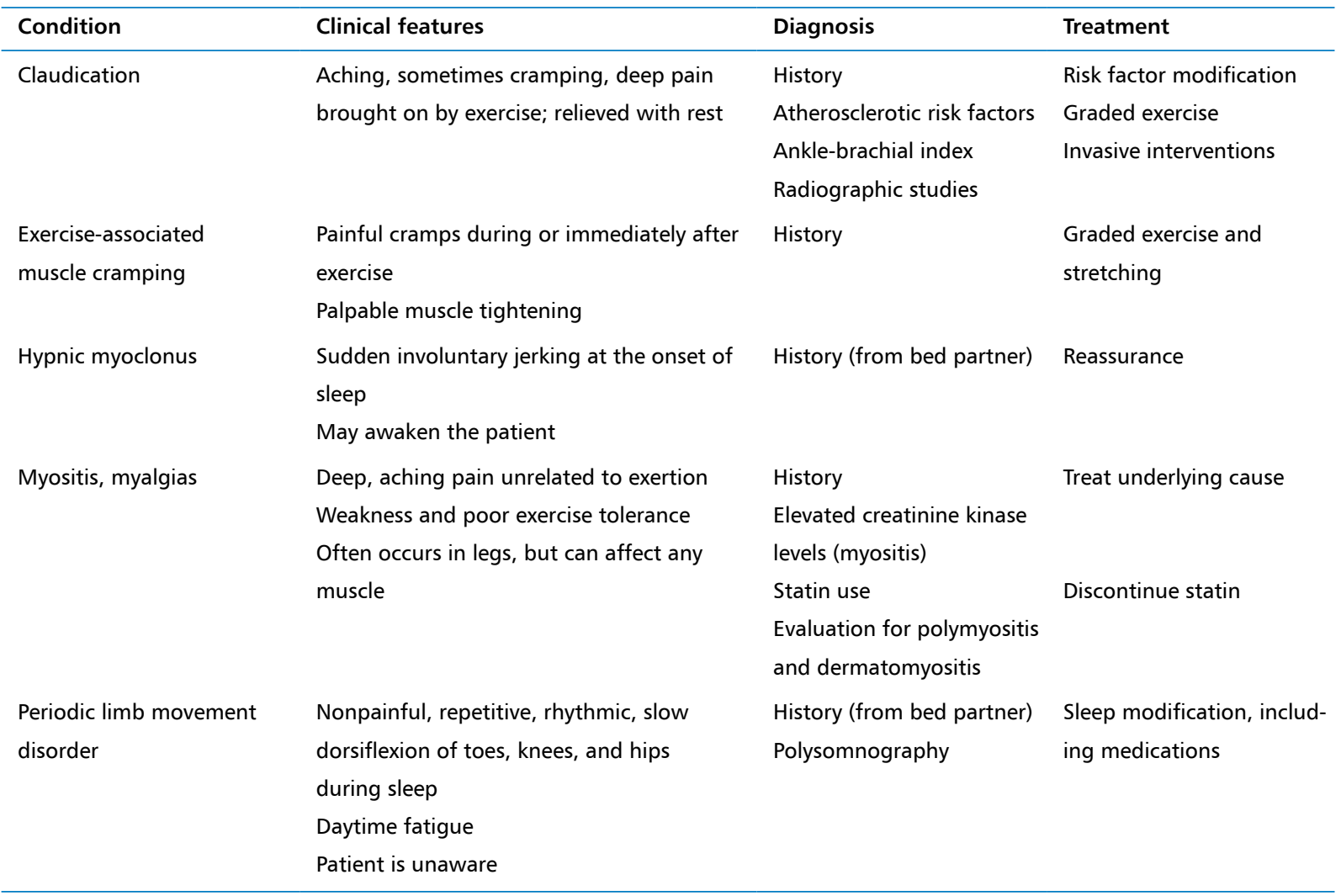

\section{Skeletal muscle lipid content and oxidative enzyme activity}

In type 2 diabetes and obese patients, a reduced oxidative enzyme activity, increased lipid content and increased glycolytic activity was observed in the skeletal muscle. Insulin resistant glucose metabolism is associated with this metabolic characteristic of the muscle [38].

\section{Differential diagnosis and evaluation of muscle cramps}

Cramps related to diabetes need to be identified carefully, condition which might mimic the diabetic cramps needs to be excluded by performing relevant test or checking the medical history of the patient. Upon exclusion of the etiologies and symptoms mentioned in Table 3, the muscle cramps related to diabetes are confirmed [51].

\section{Treatment of muscle cramps}

It is indispensable to detect underlying cause of structural and metabolic disorder leading to muscle cramps in diabetic patients. Different treatment strategies can be followed to treat acute and chronic pain in diabetes. In case of acute pain non-pharmacological strategies are adapted. Stretching or lengthening the cramps muscle stops most of the acute cramps $[52,53]$.

In the recent past, various clinical trials were conducted to check the safety and efficacy of various drugs and nutraceuticals in diabetes induced muscle cramps. Miller et al., in the year 2001, conducted a phase III clinical trial to study the effect of gabapentin (a glutamate blocking drug) on patients with ALS. It was a double-blind randomized controlled trail on 204 patients with ALS. The result of this trial was compared with the phase II trial of the same drug conducted in smaller population and for a shorter period of time [54, 55]. Despite the positive phase II trial report, the phase III trial failed to prove the therapeutic efficacy of gabapentin in patients with ALS. The encouraging phase II data was believed to be due to by chance. Finally, it was concluded that gabapentin had no therapeutic effect on patients with ALS. In another study, 28 elderly patients were enrolled to check the efficacy of vitamin $B$ complex (including vitamin $B_{6} 30 \mathrm{mg} /$ day) in reducing the nocturnal leg cramps. After three months of treatment (vitamin B complex capsule TID) $86 \%$ of patients experienced remission from muscle cramps [56]. The patients were not known to be suffering from any vitamin deficiency compared to placebo group. 
Naftidrofuryl, a vasodilator was studies in a cohort of 14 subjects suffering from rest cramps (night cramps). The effect of this drug on cerebrovascular and peripheral vascular disease was well established before. However, Young and Connolly in the year 1993, could establish its significant remedial effect on the rest cramps [57]. Naftidrofuryl could significantly reduce cramps frequency in the patients $(p<0.004)$ in this double-blind placebo-controlled trial. This drug enhances the utilization of glucose and oxygen in peripheral vascular disease and protect brain parenchyma during anoxia.

Diltiazem hydrochloride, a calcium channel blocker, used in hypertension was studied for the management of muscle cramps. In this cross-over double-blind study, 13 patients who experience two or more cramps per week were treated with $30 \mathrm{mg}$ of diltiazem hydrochloride. There was a significant $(p<0.04)$ reduction in the number of cramps in drug treated group compared to placebo [58]. This study proved the therapeutic potential of diltiazem in the management of muscle cramps.

As per recommendation of American Academy of Neurology, vitamin B complex, calcium channel blockers such as diltiazem and naftidrofuryl are effective and can be considered for use in the management of muscle cramps (level C). It has also been recommended to avoid the use of quinine derivatives (level A) owing to their potential toxicity [59]. However, quinines can be used for an individual therapeutic trial upon confirmation on the management of potential adverse effect if any.

Oxidative stress was believed to have an effect on the development of insulin resistance [60] and in some studies treatment with antioxidants seemed to improve glycine control in type 2 diabetic patients by scavenging the reactive oxygen species [61, 62]. In one recent study, high dose of vitamin E supplementation found to improve insulin action by reducing the plasma fasting insulin and glucose levels. There was also substantial decline in cellular oxidant stress and inflammatory activity [63]. Hence, in case of diabetic muscle cramps vitamin E can be used as supplement with the first-line treatment.

The effect of L-carnitine supplementation in the management of cirrhotic muscle cramps is discussed in the previous section. However, in a recent study [64], L-carnitine supplementation ( $600 \mathrm{mg} /$ day PO for 4 months) was found to improve the quality of life of diabetic patients suffering with muscle cramps. Hence, L-carnitine supplementation can be considered as an ideal strategy to manage muscle cramps in diabetic patients.

\section{Role of ubiquinone}

Two forms of Co-enzyme Q10 (CoQ10) namely ubiquinone (oxidized form) and ubiquinol (reduced form occurs naturally in human body [65] and other anaerobic organisms. The production of this enzyme reaches at its highest during mid-twenties and gradually declines with age. The concentration of this enzyme gets reduced to $50 \%$ by the time people reach 60 years of age [66]. In the recent past, it was reported that a significant decline in the level of CoQ10 in patients with type 2 diabetes is correlated with an increased plasma glucose level, $\mathrm{HbA}_{1 \mathrm{c}}$ and other oxidative stress markers [67].

The rate limiting enzyme 3-hydroxy-3-methylglutaryl-CoA reductase (HMGCR) is instrumental in the mevalonic acid path way, cholesterol biosynthesis and synthesis of CoQ10.The inhibition of HMGCR, serious muscle injuries (e.g. myopathy, myositis and rhabdomyolysis) are the adverse events of statins (e.g. atorvastatin) used in the treatment of hypercholesterolemia in type 2 diabetes [68, 69]. Hence, CoQ10 supplementation for statin induced muscle symptoms have opened a new avenue in the complementary management of statin-induced myopathy in type 2 diabetic patients [70].

\section{Special focus of muscle cramps in diabetics}

The complication of muscle cramps is a very common one in our type 2 diabetic patients and the treatment should be addressed to the underlying cause if possible or else it should be treated as per the above regimen of use of co-enzyme Q10 as part of idiopathic etiology. A summary of treatment in diabetics is shown below in Table 4 as per the major contributing factors towards cramps.

Table 4. Causes and treatments of muscle cramps in diabetics

\begin{tabular}{ll}
\hline Cause & Treatment \\
\hline Peripheral neuropathy & Standard treatment for neuropathy with tricyclic antidepressants, pregabalin, gabapentin \\
Peripheral vascular diseases & Stenting if needed, smoking cessation, cilostazol, standard treatment with statins and \\
and cardiovascular diseases & aspirin and clopidogrel \\
ESRD on maintenance hemodialysis & $\begin{array}{l}\text { Changing the sodium concentration of the dialysis fluid during the dialysis; treating } \\
\text { underlying co-existent neuropathy }\end{array}$
\end{tabular}




\section{Conclusion}

Muscle cramps in diabetes reduce the quality of life of patients. Diagnosis of muscle cramps in diabetic patients is a common problem in clinical practice. However, the mechanism and underlying cause is less well understood till date. Hence, the diagnosis of muscle cramps should prompt the physician to look for any associated comorbidities like peripheral neuropathies, metabolic disorders, cirrhosis, immune mediated myositis, and ALS etc. Although the availability of treatment is less, the physician should carefully plan the treatment protocol to manage the cramps thereby improve the quality of life of patients living with diabetes.

\section{Ethics policy}

This article does not contain any studies with human or animal subjects performed by any of the authors.

\section{Conflict of interest}

All the authors have declared to have no conflict of interest.

\section{REFERENCES}

1. Layzer RB. The origin of muscle fasciculations and cramps. Muscle Nerve. 1994; 17(11): 1243-1249, doi: 10.1002/mus.880171102, indexed in Pubmed: 7935546.

2. Miller TM, Layzer RB. Muscle cramps. Muscle Nerve. 2005; 32(4): 431-442, doi: 10.1002/mus.20341, indexed in Pubmed: 15902691.

3. Kästenbauer $T$, Irsigler $P$, Sauseng $S$, et al. The prevalence of symptoms of sensorimotor and autonomic neuropathy in Type 1 and Type 2 diabetic subjects. J Diabetes Complications. 2004; 18(1): 27-31, doi: 10.1016/S1056-8727(03)00071-0, indexed in Pubmed: 15019596.

4. Abdulla AJ, Jones PW, Pearce VR. Leg cramps in the elderly: prevalence, drug and disease associations. Int J Clin Pract. 1999; 53(7): 494-496, indexed in Pubmed: 10692732.

5. Oboler SK, Prochazka AV, Meyer TJ. Leg symptoms in outpatient veterans. West J Med. 1991; 155(3): 256-259, indexed in Pubmed: 1659038.

6. Katzberg $\mathrm{H}$, Kokokyi $\mathrm{S}, \mathrm{Halpern} \mathrm{E}$, et al. Prevalence of muscle cramps in patients with diabetes. Diabetes Care. 2014; 37(1): e17-e18, doi: 10.2337/dc13-1163, indexed in Pubmed: 24356604.

7. Bharucha NE, Bharucha AE, Bharucha EP. Prevalence of peripheral neuropathy in the Parsi community of Bombay. Neurology. 1991; 41(8): 1315-1317, doi: 10.1212/wnl.41.8.1315, indexed in Pubmed: 1650932.

8. Saha SP, Bhattacharya S, Das SK, et al. Epidemiological study of neurological disorders in a rural population of Eastern India. J Indian Med Assoc. 2003; 101(5): 299-300, 302, indexed in Pubmed: 14575218.

9. Gourie-Devi M, Gururaj G, Satishchandra P, et al. Prevalence of neurological disorders in Bangalore, India: a community-based study with a comparison between urban and rural areas. Neuroepidemiology. 2004; 23(6): 261-268, doi: 10.1159/000080090, indexed in Pubmed: 15297791.

10. Silberstein L, Britton KE, Marsh FP, et al. An unexpected cause of muscle pain in diabetes. Ann Rheum Dis. 2001; 60(4): 310-312, doi: 10.1136/ard.60.4.310, indexed in Pubmed: 11247854.
11. Jansen PH, Lecluse RG, Verbeek AL. Past and current understanding of the pathophysiology of muscle cramps: why treatment of varicose veins does not relieve leg cramps. J Eur Acad Dermatol Venereol. 1999; 12(3): 222-229, indexed in Pubmed: 10461641.

12. Féré $\mathrm{Ch}$. Les crampes et les paralysies nocturnes. Medecine moderne. In: Näcke P, editor. Zur Pathogenese und klinik der wadenkrämpfe (1901). Neurol Ztrbl. 1990: 290-296.

13. Erben $S$. Über den crampus und seine bekämpfung. Wiener klinWochenschr. 1928; 43: 1499-1501.

14. Santler R. Führen Krampfadern ihren Namen zu Recht? Wiener Kiln Wochenschr. 1971; 83: 808-814.

15. Santler R. Krampfadern und krämpfe. Z Haut-Geschl Kr. 1971; 19: 696-703.

16. Perchuk $E$. The diagnosis and treatment of nocturnal leg cramps. Clin Med. 1964; 71: 1167-1174.

17. Gonce M, Delwaide PJ. Les crampesmusculaires. Rev Med Liege. 1982; 37: 274-279.

18. Nicholson J, Falk A. Night cramps in young men. N Engl J Med. 1945; 233(19): 556-559, doi: 10.1056/nejm194511082331902.

19. Strümpell A. Dtsch Z Nervenheilk. 1921; 72: 118.

20. Grund G. Der lokale Muskelcrampus als Tonusphänomen. Dtsch Z Nervenheilk. 1927; 97(1-3): 1-9, doi: 10.1007/bf01667899.

21. Barclay CJ. Models in which many cross-bridges attach simultaneously can explain the filament movement per ATP split during muscle contraction. Int J Biol Macromol. 2003; 32(3-5): 139-147, doi: 10.1016/s0141-8130(03)00047-3, indexed in Pubmed: 12957310.

22. Nakanishi $H$, Kurosaki M, Tsuchiya $K$, et al. L-carnitine reduces muscle cramps in patients with cirrhosis. Clin Gastroenterol Hepatol. 2015; 13(8): 1540-1543, doi: 10.1016/j.cgh.2014.12.005, indexed in Pubmed: 25496816.

23. Wernicke $C$. Ein fall von Crampus-Neurose. Berliner KlinWochenschr. 1904; 43: 1121-1124.

24. Klimke W. Über lokalisierte Muskelkrampfzustände und ihre Entstehung. Zeitschrift für die gesamte Neurologie und Psychiatrie. 1936; 155(1): 592-607, doi: 10.1007/bf02865586.

25. Katzberg HD, Katzberg HD. Neurogenic muscle cramps. J Neurol. 2015; 262(8): 1814-1821, doi: 10.1007/s00415-015-7659-x, indexed in Pubmed: 25673127.

26. Ballout RA, Arabi A. Painful and prolonged muscle cramps following insulin injections in a patient with type 2 diabetes mellitus: revisiting the 1992 duke case. Front Endocrinol (Lausanne). 2017; 8: 243, doi: 10.3389/fendo.2017.00243, indexed in Pubmed: 28993757.

27. Habib GS, Nashashibi M, Saliba W, et al. Diabetic muscular infarction: emphasis on pathogenesis. Clin Rheumatol. 2003; 22(6): 450-451, doi: 10.1007/s10067-003-0789-z, indexed in Pubmed: 14677026.

28. Matsumoto M, Watanabe $K$, Tsuji T, et al. Nocturnal leg cramps: a common complaint in patients with lumbar spinal canal stenosis. Spine (Phila Pa 1976). 2009; 34(5): E189-E194, doi: 10.1097/ BRS.0b013e31818f953c, indexed in Pubmed: 19247159.

29. Baskol M, Ozbakir O, Coşkun R, et al. The role of serum zinc and other factors on the prevalence of muscle cramps in nonalcoholic cirrhotic patients. J Clin Gastroenterol. 2004; 38(6): 524-529, doi: 10.1097/01.mcg.0000129059.69524.d9, indexed in Pubmed: 15220689.

30. Steiner I, Siegal T. Muscle cramps in cancer patients. Cancer. 1989; 63(3): 574-577, indexed in Pubmed: 2912532.

31. Allen RE, Kirby KA. Nocturnal Leg Cramps. https://www.aafp.org/ afp/2012/0815/p350.html. Accessed April. ; 19: 2019.

32. Meyer AH, Kirkman MS. Shock and prolonged muscle cramps after intravenous insulin therapy. N C Med J. 1992; 53(9): 484-486, indexed in Pubmed: 1407029.

33. Denny-Brown D. Clinical problems in neuromuscular physiology. Am J Med. 1953; 15(3): 368-390, doi: 10.1016/00029343(53)90090-4, indexed in Pubmed: 13080284.

34. Maxwell SK, Kokokyi S, Breiner A, et al. Characteristics of muscle cramps in patients with polyneuropathy. Neuromuscul Disord. 
2014; 24(8): 671-676, doi: 10.1016/j.nmd.2014.04.008, indexed in Pubmed: 24878228.

35. Howe RC, Wombolt DG, Michie DD. Analysis of tonic muscle activity and muscle cramps during hemodialysis. J Dial. 1978; 2(1): 85-99, doi: 10.3109/08860227809103866, indexed in Pubmed: 641247

36. Garrison SR, Dormuth CR, Morrow RL, et al. Nocturnal leg cramps and prescription use that precedes them: a sequence symmetry analysis. Arch Intern Med. 2012; 172(2): 120-126, doi: 10.1001/ archinternmed.2011.1029, indexed in Pubmed: 22157068.

37. Mosenkis A, Townsend RR. Muscle cramps and diuretic therapy. J Clin Hypertens (Greenwich). 2005; 7(2): 134-135, doi: 10.1111/j.1524-6175.2005.04094.x, indexed in Pubmed: 15722661.

38. Mulder DW. The clinical syndrome of amyotrophic lateral sclerosis. Proc Staff Meet Mayo Clin. 1957; 32(17): 427-436, indexed in Pubmed: 13465821.

39. de Vries PM, Kouw PM, Olthof CG, et al. The influence of dialysate sodium and variable ultrafiltration on fluid balance during hemodialysis. ASAIO Trans. 1990; 36(4): 821-824, doi: 10.1097/00002480-199010000-00008, indexed in Pubmed: 2268486.

40. de Vries PM, Olthof CG, Solf $A$, et al. Fluid balance during haemodialysis and haemofiltration: the effect of dialysate sodium and a variable ultrafiltration rate. Nephrol Dial Transplant. 1991; 6(4): 257-263, doi: 10.1093/ndt/6.4.257, indexed in Pubmed: 1881579.

41. Martinez-Huenchullan S, Ban L, Tao A, et al. Diabetes and highfat diet induce different pathologies in mouse skeletal muscle extracellular matrix. Diabetes. 2018; 67(Supplement 1), doi: 10.2337/db18-1923-p.

42. Cree-Green M, Scalzo RL, Harrall K, et al. Supplemental oxygen improves in vivo mitochondrial oxidative phosphorylation flux in sedentary obese adults with type 2 diabetes. Diabetes. 2018; 67(7): 1369-1379, doi: 10.2337/db17-1124, indexed in Pubmed: 29643061.

43. Koves TR, Ussher JR, Noland RC, et al. Mitochondrial overload and incomplete fatty acid oxidation contribute to skeletal muscle insulin resistance. Cell Metab. 2008; 7(1): 45-56, doi: 10.1016/j. cmet.2007.10.013, indexed in Pubmed: 18177724.

44. Ritov VB, Menshikova EV, He J, et al. Dysfunction of mitochondria in human skeletal muscle in type 2 diabetes. Diabetes. 2002; 51(10): 2944-2950, doi: 10.2337/diabetes.51.10.2944, indexed in Pubmed: 12351431.

45. Laufs U, Scharnagl H, Halle M, et al. Treatment options for statinassociated muscle symptoms. Dtsch Arztebl Int. 2015; 112(44): 748-755, doi: 10.3238/arztebl.2015.0748, indexed in Pubmed: 26575138.

46. Kapoor P, Kapoor AK. Coenzyme Q10 - A novel molecule. J Ind Med Clin Med. 2013; 14: 37-45.

47. Lawrence HW, Randy JF. The musculoskeletal effects of diabetes mellitus. J Can Chiropr Assoc. 2006; 50: 43-50.

48. Hertz G, Fast A, Feinsilver $\mathrm{SH}$, et al. Sleep in normal late pregnancy. Sleep. 1992; 15(3): 246-251, doi: 10.1093/sleep/15.3.246, indexed in Pubmed: 1621025.

49. Palsgaard J, Brøns C, Friedrichsen M, et al. Gene expression in skeletal muscle biopsies from people with type 2 diabetes and relatives: differential regulation of insulin signaling pathways. PLoS One. 2009; 4(8): e6575, doi: 10.1371/journal.pone.0006575, indexed in Pubmed: 19668377.

50. Zacks SI. Myopathies related to diabetes mellitus and other metabolic diseases. Ann Clin Lab Sci. 1975; 5(4): 248-251, indexed in Pubmed: 1057868.

51. Buckley AF, Bossen EH. Skeletal muscle microvasculature in the diagnosis of neuromuscular disease. J Neuropathol Exp Neurol. 2013; 72(10): 906-918, doi: 10.1097/NEN.0b013e3182a7f0b8, indexed in Pubmed: 24042201.

52. He J, Watkins S, Kelley DE. Skeletal muscle lipid content and oxidative enzyme activity in relation to muscle fiber type in type 2 diabetes and obesity. Diabetes. 2001; 50(4): 817-823, doi: 10.2337/diabetes.50.4.817, indexed in Pubmed: 11289047.
53. Davison S. Standing: a good remedy. JAMA. 1984; 252(24): 3367, indexed in Pubmed: 6502901.

54. Fowler AW. Relief of cramp. Lancet. 1973; 1(7794): 99, doi: 10.1016/s0140-6736(73)90492-3, indexed in Pubmed: 4118671.

55. Miller RG, Moore DH, Gelinas DF, et al. Western ALS Study Group. Phase III randomized trial of gabapentin in patients with amyotrophic lateral sclerosis. Neurology. 2001; 56(7): 843-848, doi: 10.1212/wnl.56.7.843, indexed in Pubmed: 11294919.

56. Miller RG, Moore D, Young LA, et al. Placebo-controlled trial of gabapentin in patients with amyotrophic lateral sclerosis. WALS Study Group. Western Amyotrophic Lateral Sclerosis Study Group. Neurology. 1996; 47(6): 1383-1388, doi: 10.1212/wnl.47.6.1383, indexed in Pubmed: 8960715.

57. Young JB, Connolly MJ. Naftidrofuryl treatment for rest cramp. Postgrad Med J. 1993; 69(814): 624-626, doi: 10.1136/pgmj. 69.814.624, indexed in Pubmed: 8234106.

58. Voon WC, Sheu SH. Diltiazem for nocturnal leg cramps. Age Ageing. 2001; 30(1): 91-92, doi: 10.1093/ageing/30.1.91, indexed in Pubmed: 11322688.

59. Katzberg HD, Khan AH, So YT. Assessment: symptomatic treatment for muscle cramps (an evidence-based review): report of the therapeutics and technology assessment subcommittee of the American academy of neurology. Neurology. 2010; 74(8): 691-696, doi: 10.1212/WNL.0b013e3181d0ccca, indexed in Pubmed: 20177124.

60. Evans JL, Goldfine ID, Maddux BA, et al. Are oxidative stress-activated signaling pathways mediators of insulin resistance and beta-cell dysfunction? Diabetes. 2003; 52(1): 1-8, doi: 10.2337/ diabetes.52.1.1, indexed in Pubmed: 12502486.

61. Paolisso G, D'Amore A, Galzerano D, et al. Daily vitamin E supplements improve metabolic control but not insulin secretion in elderly type II diabetic patients. Diabetes Care. 1993; 16(11): 1433-1437, doi: 10.2337/diacare.16.11.1433, indexed in Pubmed: 8299431.

62. Jacob S, Ruus P, Hermann R, et al. Oral administration of RAC-alpha-lipoic acid modulates insulin sensitivity in patients with type-2 diabetes mellitus: a placebo-controlled pilot trial. Free Radic Biol Med. 1999; 27(3-4): 309-314, doi: 10.1016/s08915849(99)00089-1, indexed in Pubmed: 10468203.

63. Manning PJ, Sutherland WHF, Walker RJ, et al. Effect of highdose vitamin $\mathrm{E}$ on insulin resistance and associated parameters in overweight subjects. Diabetes Care. 2004; 27(9): 2166-2171, doi: 10.2337/diacare.27.9.2166, indexed in Pubmed: 15333479.

64. Imbe A, Tanimoto $K$, Inaba $Y$, et al. Effects of L-carnitine supplementation on the quality of life in diabetic patients with muscle cramps. Endocr J. 2018; 65(5): 521-526, doi: 10.1507/endocrj. EJ17-0431, indexed in Pubmed: 29515058.

65. Mantle D. Coenzyme Q10 supplementation for diabetes and its complications: an overview. Br J Diabetes. 2017; 17(4): 145-148, doi: 10.15277/bjd.2017.149.

66. Weber C, Bysted A, Hilmer G. The coenzyme Q10 content of the average Danish diet. Int J Vitam Nutr Res. 1997; 67(2): 123-129, indexed in Pubmed: 9129255.

67. El-Ghoroury EA, Raslan HM, Badawy EA, et al. Malondialdehyde and coenzyme Q10 in platelets and serum in type 2 diabetes mellitus: correlation with glycemic control. Blood Coagul Fibrinolysis. 2009; 20(4): 248-251, doi: 10.1097/mbc.0b013e3283254549, indexed in Pubmed: 19530339.

68. Choi HK, Won EK, Choung SY. Effect of coenzyme Q10 supplementation in statin-treated obese rats. Biomol Ther (Seoul). 2016; 24(2): 171-177, doi: 10.4062/biomolther.2015.089, indexed in Pubmed: 26797109.

69. Pasha R, Moon TW. Coenzyme Q10 protects against statin-induced myotoxicity in zebrafish larvae (Danio rerio). Environ Toxicol Pharmacol. 2017; 52: 150-160, doi: 10.1016/j.etap.2017.03.021, indexed in Pubmed: 28414942.

70. Qu H, Guo M, Chai H, et al. Effects of Coenzyme Q10 on Statin-Induced Myopathy: An Updated Meta-Analysis of Randomized Controlled Trials. J Am Heart Assoc. 2018; 7(19): e009835, doi: 10.1161/JAHA.118.009835, indexed in Pubmed: 30371340. 